\title{
Implantação e implementação da Educação Física inclusiva
}

\author{
Eliana Lúcia Ferreira*
} Carolina Lessa Cataldi**

\section{Resumo}

A Educação Física, como um dos componentes curriculares da educação básica, não está indiferente ao movimento da Educação Inclusiva. Corpos diferenciados estão conquistando um novo espaço social. Sendo assim, esta pesquisa tem como objetivo, identificar os principais apontamentos históricos da Política de Educação Inclusiva brasileira e sugerir uma proposta de implementação da Educação Física escolar inclusiva. Metodologicamente, este é um estudo caracterizado como uma pesquisa descritiva, edificada em dois eixos principais: o primeiro discute os apontamentos históricos, apoiado em documentos nacionais de referências sobre a Educação Física Inclusiva e o segundo, é baseado na experiência de 2000 professores, analisando suas práticas inclusivas. Como resultado dessa análise, surge uma proposta de Educação Física Inclusiva, que erige em uma outra dimensão de trabalho/movimento. Nas considerações finais, sugere-se quebrar/desestabilizar com as práticas corporais já cristalizadas e atuar com aquelas que respeitam as diferenças de cada um. Além disso, aponta que a Educação Física Inclusiva tem preconizado outro significado de corpo, pois prevalece, em suas atividades, a busca do individual, em prol de uma Educação Física mais coletiva.

Palavras-chave: Educação Física Inclusiva; Pessoas com Deficiência; Inclusão Social.

* Professora Doutora da Universidade Federal de Juiz de Fora, São Pedro, Juiz de Fora, Minas Gerais, Brasil.

** Mestranda em Educação Física pela Universidade Federal de Juiz de Fora, São Pedro, Juiz de Fora, Minas Gerais, Brasil. 


\section{Deploying and implementing Inclusive Physical Education}

\section{Abstract}

Physical Education, as a curricular component of basic education, is not indifferent to the movement of Inclusive physical education. Differentiated bodies are conquering new social spaces. Our aim through this investigation is to identify the main historical practices regarding Brazilian Policy of Inclusive Education and to point out proposals to implement inclusive Physical education. Our methodology consists of a descriptive study based on two main axes. The first axis is related to a historical discussion whose source was national documents of reference about Inclusive Physical Education. The second axis is related to the experience of 2000 teachers; we have the occasion to analyze their practices on the subject of Inclusive physical education. As a result, this investigation also develops a proposal to inclusive physical education; this proposal is established in another dimension and understanding of work and movement. Concerning the final considerations we suggest a disruption with already crystallized bodily practices and we suggest actions respecting individual differences. Moreover, we point out the fact that Inclusive Physical Education has advocated another meaning for the body, in favor of a more collective physical education and searching for activities in which individuality prevails.

Keywords: Inclusive Physical Education; Disable people; Social Inclusion.

\section{Introdução}

A inclusão tem sido conceituada como um processo que deve eliminar as barreiras que limitam a presença, aprendizagem e participação das pessoas com deficiência na sociedade.

Os conceitos e as concepções equivocados sobre deficiência ainda fazem parte do imaginário social, o que acarreta sérias atitudes de exclusão (BISSOTO, 2013).

Entendendo a real necessidade de mudança nesse quadro, a legislação de atendimento educacional especializado nos estabelecimentos de ensino norteado pela Lei de Diretrizes e Bases da Educação Brasileira (LDB n 9394/96) e pela Política Nacional da Educação Especial na Perspectiva da Educação Inclusiva (Portaria no 555/2007) assim como as Leis $\mathrm{n}^{\mathrm{O}} 10.048$ de 8 de novembro de 2000 e ํㅡㄴ 10.098 de 19 de dezembro de 2000, estabelecem normas gerais e critérios básicos para a promoção da acessibilidade e da inclusão das pessoas com deficiência no âmbito social, cultural e educacional. 
Tradicionalmente, as aulas regulares são organizadas e planejadas supondo alunos homogêneos, o que deixa os alunos com deficiência limitados no que tange os seus direitos de participação efetiva nas atividades propostas (ECHEITA, 2009). Por outro lado, a Educação, como instância mediadora, é ao mesmo tempo o exercício de um direito e a possibilidade de ampliação do acesso a outros direitos fundamentais.

Nesta perspectiva, a Educação Física, como um dos componentes curriculares da educação básica, não está indiferente ao movimento da Educação Inclusiva. Como faz parte integrante do currículo oferecido pela escola, essa disciplina constitui-se num dos adjuvantes do processo da inclusão escolar e esportiva.

A atividade física e desportiva para as pessoas com deficiência cresceu muito desde os anos de 1980. Eventos, publicações e ações governamentais, a partir desse período, marcaram esse crescimento. Mas, Carmo (2011), aponta que: poucos se preocuparam com a relação Educação Física/Inclusão, mesmo porque o trabalho tem se restringido aos Esportes Adaptados, incompatíveis com as idéias inclusivistas.

A inclusão de alunos com deficiência nas aulas de Educação Física é uma exigência legislativa. Entretanto, a presença cada vez mais marcante das pessoas com deficiência na rede de ensino escolar requer especificidades de pessoas e de conteúdos. Nessa perspectiva, este estudo tem como objetivo, identificar os principais apontamentos históricos da Política de Educação Inclusiva brasileira e apontar propostas de implementação da Educação Física escolar inclusiva.

A presença de pessoas com deficiência na rede de ensino é assegurada pelos direitos à igualdade de oportunidades e à participação social (AMARAL, et. al, 2012). No entanto, não se trata apenas, de garantir o direito ao acesso ou somente reconhecer o direito à igualdade de oportunidade criando alternativas pedagógicas adequadas distintas, que equiparem as condições de pessoas que não se encontram em condições de deficiência; mas sim, assegurar e dar condições para que a permanência destes alunos na escola aconteça com sucesso. Esta permanência com sucesso implica na possibilidade de usufruir de condições necessárias a equiparação das condições oferecidas aos demais alunos da instituição.

\section{Material e método}

O presente estudo pode ser caracterizado como uma pesquisa descritiva, edificada em dois eixos principais. Um que procurou na produção científica da área: conhecer os apontamentos históricos da Política de Educação Inclusiva brasileira e, outro, para subsidiar nossa proposta de Educação Física Inclusiva: buscou conhecer a prática diária de 2000 professores da rede municipal de ensino das diversas regiões do Brasil, regularmente matriculados no curso a distância de Aperfeiçoamento em Atividade Física para Pessoas com Deficiência, desenvolvido pela Universidade Federal de Juiz de Fora (UFJF) e financiado pelo Ministério de Educação e Cultura (MEC), no período de 2008 a 2012. 
No primeiro momento, foi realizada ampla revisão bibliográfica rastreando artigos científicos. A busca, entretanto, limitou-se aos trabalhos indexados e catalogados, com as palavras chaves: Educação Física e Inclusão; Atividade Física e Inclusão e Esporte e Inclusão.

Apresentaremos abaixo, no quadro 1 , o mapeamento realizado dos periódicos consultados, situados nos extratos (B1, B2, B3, B4)1, de acordo com a Área 21 (Educação Física), do Qualis referente ao triênio 2010 - 2012, disponíveis on- line, e que discutiram, nos últimos dez anos, a questão da Educação Física Inclusiva. É importante ressaltar, que não foram encontradas publicações de artigos sobre o tema, nos extratos B3.

Quadro 1 - Periódicos com classificação B1 pela CAPES, na área da Educação Física e número de artigos que contemplam educação física e inclusão.

\begin{tabular}{|l|c|c|}
\hline \multicolumn{1}{|c|}{ Periódicos } & Instituição & N \\
\hline Movimento & UFRGS & 8 \\
\hline Motricidade & FTCD/FIP-MOC & 0 \\
\hline $\begin{array}{l}\text { Revista Brasileira de } \\
\text { Ciências do Esporte }\end{array}$ & CBCE & 5 \\
\hline $\begin{array}{l}\text { Revista Brasileira de } \\
\text { Educação Física e Esporte }\end{array}$ & USP & 2 \\
\hline $\begin{array}{l}\text { Revista Brasileira de } \\
\text { Educação Especial }\end{array}$ & ABPEE & 2 \\
\hline Educação em Revista & UFMG & 0 \\
\hline Educação e Pesquisa & USP & 0 \\
\hline Educação \& Sociedade & CEDES & 0 \\
\hline
\end{tabular}

Quadro 2 - Periódicos com classificação B2 pela CAPES, na área da Educação Física e número de artigos que contemplam educação física e inclusão.

\begin{tabular}{|l|c|c|}
\hline \multicolumn{1}{|c|}{ Periódicos } & Instituição & N \\
\hline $\begin{array}{l}\text { Revista Brasileira de } \\
\text { Atividade Física e Saúde }\end{array}$ & SBAFS & 1 \\
\hline $\begin{array}{l}\text { Revista da Educação Física } \\
\text { da UEM(online) }\end{array}$ & UEM & 4 \\
\hline $\begin{array}{l}\text { Revista Brasileira de Ciência } \\
\text { e Movimento }\end{array}$ & UCB - DF & 1 \\
\hline Pensar a Prática & UFG & 5 \\
\hline Educar em Revista & UFPR & 0 \\
\hline Licere & UFMG & 0 \\
\hline
\end{tabular}

Quadro3 - Periódicos com classificação B4 pela CAPES, na área da Educação Física e número de artigos que contemplam educação física e inclusão. 


\begin{tabular}{|l|c|c|}
\hline \multicolumn{1}{|c|}{ Periódicos } & Instituição & N \\
\hline Motrivivência & UFSC & 0 \\
\hline Arquivos em Movimento & EEFD/UFRJ & 1 \\
\hline Revista Educação Especial & UFSM & 5 \\
\hline $\begin{array}{l}\text { Revista Mackenzie de } \\
\text { Educação Física e Esporte }\end{array}$ & REMEFE & 1 \\
\hline
\end{tabular}

Em seguida, foi então realizada a coleta de dados, que se deu através da análise das atividades postadas pelos alunos do curso já mencionado, no Ambiente Virtual de Aprendizagem utilizado - Plataforma Moodle 2 - como exigência para a conclusão do referido curso. As atividades analisadas contemplaram apenas aquelas que continham os resultados de "estudos de casos" sobre atividades físicas inclusivas.

Nas tabelas abaixo, demonstraremos a divisão por região e área de atuação, dos alunos participantes do curso.

\begin{tabular}{lcccccc}
\hline REGIÃO & \multicolumn{2}{c}{2009} & \multicolumn{2}{c}{2010} & \multicolumn{2}{c}{2011} \\
& $\mathrm{~N}$ & $\%$ & $\mathrm{~N}$ & $\%$ & $\mathrm{~N}$ & $\%$ \\
Norte & 14 & 5,6 & 8 & 3,2 & 15 & 1 \\
Sul & 67 & 26,8 & 30 & 12 & 169 & 11,5 \\
Sudeste & 92 & 36,8 & 132 & 53 & 735 & 50 \\
Nordeste & 41 & 16,4 & 25 & 10 & 342 & 23,2 \\
Centro-oeste & 36 & 14,4 & 54 & 21,6 & 208 & 14,2 \\
TOTAL & 250 & - & 249 & - & 1469 & - \\
\hline
\end{tabular}

Tabela 1. Número e percentual de participantes dos cursos e respectivas regiões.

O material encontrado foi lido e analisado na perspectiva de identificar atividades, saberes e métodos que respondessem à seguinte questão: como trabalhar com a Educação Física Inclusiva?

\begin{tabular}{lcccccc}
\hline FUNÇÃO & \multicolumn{2}{c}{2009} & \multicolumn{2}{c}{2010} & \multicolumn{2}{c}{2011} \\
& $\mathrm{~N}$ & $\%$ & $\mathrm{~N}$ & $\%$ & $\mathrm{~N}$ & $\%$ \\
& & & & & & \\
Professor & 188 & 75,2 & 214 & 85,9 & 1164 & 79,2 \\
$\begin{array}{l}\text { Coordenador } \\
\text { Pedagógico }\end{array}$ & 22 & 8,8 & 13 & 5,2 & 81 & 5,5 \\
Outros & 40 & 16 & 22 & 8,8 & 224 & 15,2 \\
TOTAL & 250 & - & 249 & - & 1469 & - \\
\hline
\end{tabular}

Tabela 2. Número de professores, coordenadores pedagógicos e outros (secretários, diretores, etc.) participantes do curso. 


\section{O aluno com deficiência nas aulas de Educação Física: apontamentos históricos}

Historicamente, muitas ações têm sido desenvolvidas na busca de uma Educação Física mais inclusiva. Podemos citar como exemplo, a Campanha Nacional de Educação de Cegos (CNEC), a Campanha Nacional de Educação e Reabilitação dos Deficientes Mentais (CADEME); o Centro Nacional de Educação Especial (CENESP); o I Plano Nacional de Educação Especial (PNEE). Entretanto, a mola propulsora para atividades escolares de Educação Física se deu a partir da Campanha do Esporte para Todos (EPT) (BRASIL, 1983).

A Carta Européia do Esporte para Todos procurava criar e consolidar a área do esporte não-formal, dentro da perspectiva da educação permanente e do desenvolvimento cultural. Sua importância foi decisiva para o impulso das políticas nacionais da Educação Física e do Esporte. Esse documento foi estruturado em cinco textos, cabendo aqui ressaltar, mais especificamente, a segunda resolução do segundo texto, que se refere ao papel das autoridades públicas no desenvolvimento do esporte para todos. Sobre esta resolução, Cavalcanti (1984) diz que "numa perspectiva de educação permanente, devem ser estabelecidas relações mais estreitas entre Educação Física, o esporte escolar e o esporte voluntário". A partir daí, através da Lei n. ${ }^{\circ}$ 6.251/75 de 8 de outubro de 1975, foram instituídas as normas gerais sobre desportos, sendo oficializada a denominação desporto de massa. Como resultado da referida Lei, foi elaborado e implantado o Plano Nacional de Educação Física e Desportos (PNED), concebendo o Esporte para Todos, através da criação da área do desporto de massa para o sistema esportivo brasileiro.

Dentre os diversos aspectos do EPT, torna-se relevante citar a igualdade de oportunidade. Segundo Valente (1997), o EPT defendia a idéia de que todos deveriam ter direito à prática do esporte: "Deve-se 'democratizar' o esporte, oferecendo igualdade de acesso à prática esportiva, independentemente de idade, sexo ou condição social...". Este movimento teve uma grande relevância social. Espalhando-se por todo o território nacional, resultou em grandes eventos voltados para a prática das atividades físicas informais.

Embora a proposta do EPT não tenha incluído, de modo específico, a pessoa com deficiência, ela também não o excluiu. Assim, o programa deu margem para a discussão dessas questões. Surgiu, a partir daí, a oportunidade de participação de pessoas com deficiência na prática das modalidades esportivas. O grande marco de relevância internacional aconteceu em 1981, com a proclamação do Ano Internacional para as Pessoas Deficientes.

Outro ponto da importância do EPT para a pessoa com deficiência está nos eventos científicos realizados em Congressos Brasileiros do Esporte para Todos, realizados nos anos de 1982, 1984 e 1986. 
Em 1982, o Congresso Brasileiro do Esporte para Todos, realizado em Curitiba, Paraná, apresentou um fórum de discussão e apresentação de trabalhos desenvolvidos com as pessoas com deficiência. Através desse congresso, ocorreram as primeiras publicações, em Anais, de uma discussão sobre a importância das atividades físicas para os mesmos. Num dos trabalhos ali apresentados, diz-se que:

A ideia de que o deficiente, seja físico, mental ou social, é um limitado, um ser fora do contexto, está firmemente associada à ideia de uma sociedade em que todos têm um papel preestabelecido a exercer. Com a chegada do EPT na Bahia, mudou a concepção do que o excepcional pode fazer na sociedade. Agora, a pessoa deficiente em Salvador é uma peça de produção: tem agora um papel social... (BRASIL, 1983)

O II Congresso Brasileiro de Esporte para Todos, foi realizado em Belo Horizonte e em Santos, em 1984. Nos debates e discussões foi demonstrada a necessidade de estudos na área da Educação Física Especial e a importância da fundamentação metodológica dessa área emergente. Algumas dessas discussões foram retomadas e reforçadas no III Congresso realizado em Campo Grande, em 1986. Devido ao número crescente de trabalhos apresentados nos Congressos do EPT, foi detectada, pelo governo, a necessidade de se criar uma política voltada para as questões relacionadas com a Educação Física e o Desporto para as pessoas com deficiência. Então, no final do governo João Figueiredo, em 1984, foi criado o Projeto Integrado, Secretaria de Educação à Distância/ Centro Nacional de Educação Especial (SEED/CENESP), cujo objetivo era investigar a ausência de uma Política Nacional de Educação Física, Desporto e Esporte para Todos, voltada para as necessidades das pessoas com deficiência.

Como resultado desse trabalho, foi realizado, em Janeiro de 1985, na cidade do Rio de Janeiro, o I Fórum Nacional "O excepcional e a política de educação física, desportos e esporte para todos", que tinha como objetivo, nas discussões, formar uma consciência nacional para influenciar a criação de uma política de Educação Física e Desporto voltada para as pessoas com deficiência. Em junho de 1985, foi realizado em Brasília o Encontro Nacional "A pessoa deficiente e sua problemática". A equipe responsável pelo evento elaborou um documento que apontou algumas alternativas como propostas para a superação do descaso das pessoas com deficiência.

Já, no governo José Sarney, foi constituído, em quatro de novembro de 1985, um comitê responsável para elaborar o Plano Nacional de Ação Conjunta para Integração da pessoa deficiente. Esse Plano tinha como objetivo aprimorar a Educação Especial e a integração dessas pessoas na sociedade, apontado como propósito da Nova República estender a todos os cidadãos a oportunidade de acesso à Educação (BRASIL, 1985). Estas reivindicações foram atendidas através da resolução no 3, em 16/07/87, que somente foram efetivadas em 1988.

Essa nova proposta de Educação Especial foi fundamentada nos objetivos da Educação Básica - Educação para todos, alicerçando-se nos seguintes princípios: "Participação, integração, normalização, interiorização, e simplificação" (BRASIL, 
1985). Em relação às medidas desse Plano Nacional, Carmo (1988) aponta que a visão sobre a questão da pessoa com deficiência é uma visão superficial. A partir da política implantada com o Plano Nacional, foi proposta a reformulação do CENESP. Através do Decreto n⿳⺈ 93.613 de 21 de novembro de 1986, o órgão foi transformado na Secretária de Educação Especial (SEESP), efetivando a criação da Coordenadoria para Integração da Pessoa com Deficiência (CORDE).

Após diversas mudanças de ministérios e secretárias através de decretos, atualmente a CORDE se encontra na Secretaria dos Direitos da Cidadania - SDC, do Ministério da Justiça, tendo como metas questões relativas à integração da pessoa com deficiência.

\section{Os Planos Nacionais}

Durante algum tempo, vários encontros foram realizados no Brasil, patrocinados pela Secretaria de Estado e Cultura (SEEC/MEC). O objetivo era traçar diretrizes para favorecer a integração da Educação Física e Desportos ao contexto da Educação Especial.

Como resultados desses encontros, alguns documentos foram criados. Entre eles, a Carta de Batatais de 1986, e a Carta Internacional de Educação Física e Desportos de 1978. Neste último, a Organização das Nações Unidas para a Educação, a Ciência e a Cultura (UNESCO) estabelece que a Educação Física seja um direito fundamental de todos.

Esses documentos procuraram garantir a prática da Educação Física e do desporto como um direito fundamental de todos, sugerindo ao Estado que implantasse programas de Educação Física, desporto e lazer para pessoas com deficiência que garantissem a participação das pessoas com deficiência nos eventos desportivos oficiais e privados; a inclusão do professor licenciado em Educação Física na equipe interdisciplinar que atendesse a estas pessoas e a criação e/ou melhoria de espaços físicos adequados à prática da Educação Física, nos Centros de Reabilitação e Hospitais.

Já, no governo de Fernando Collor, através da Lei n.ำ 8.028 de 12 de abril de 1990, foi criada a Secretaria dos Desportos, cujo objetivo era estabelecer a importância e o direito de todos os cidadãos à prática de desporto como melhoria da qualidade de vida da população. Entre os princípios do programa estava "o fomento e promoção do desporto das pessoas portadoras de deficiência".

Em 1992, a CORDE implantou uma Nova Política Nacional de Integração da Pessoa Portadora de Deficiência, elaborando linhas de ação "para fazer cumprir a obrigação do Estado e da Sociedade de proporcionarem atendimento aos cidadãos portadores de deficiência". Essa Política Nacional destinou-se à integração das pessoas com deficiência na sociedade, objetivando lhes dar o usufruto dos bens e serviços disponíveis em comum com os demais cidadãos. 
Com a saída do presidente Collor, através de seu impeachment, em 1993, assumiu a presidência o vice-presidente Itamar Franco. Durante o seu mandato, Itamar transformou a Secretaria de Esporte em departamento do Ministério de Educação e Cultura. Criou o Departamento de Esporte para as pessoas com deficiência, cujo objetivo era a realização de eventos e capacitação técnica.

Já, no mandato do Presidente Fernando Henrique Cardoso, foi criado o cargo de Ministro de Estado Extraordinário dos Esportes. Tratado como um Ministério, deu-se a oportunidade de criação do Instituto Nacional de Desenvolvimento do Desporto (INDESP) (BRASIL, 2012). Sua proposta:

O estado promoverá a criação de programas de prevenção e atendimento especializados para os portadores de deficiência física, sensoriais ou mental, bem como a integração social do adolescente portador de deficiência, mediante o treinamento para o trabalho e a convivência e a facilidade do acesso aos bens e serviços. (art. 227, $\$ 1^{\circ}$, II, da CF/88)

Mas o tempo de vigência do INDESP já estava comprometido, já que ele, após a finalização do mandato do Ministro Extraordinário dos Desportos, Edson Arantes do Nascimento, o Pelé, voltou a ser vinculado ao MEC.

Ainda, no Governo do presidente Fernando Henrique Cardoso, o Novo Plano Nacional de Educação reconheceu que o atendimento existente hoje, é não só reduzido, como também precário. Não apresenta nenhuma proposta consistente, e explicita dificuldades na sua implantação (BRASIL, 2001).

Já, no Governo Lula, foi lançado pelo MEC, o Plano de Desenvolvimento da Educação: razões, princípios e programas, reafirmando a visão que busca superar a oposição entre Educação Regular e Educação Especial, criticando a forma como a segunda se estruturou, até aquele momento, em relação à Educação geral.

Dando continuidade às ações de superação da oposição citada acima, ainda em 2007, foi publicado o Decreto nํㅜ 6.094/2007, que "estabelece nas diretrizes do Compromisso Todos pela Educação, a garantia do acesso e permanência no ensino regular e o atendimento às necessidades educacionais especiais dos alunos, fortalecendo a inclusão educacional nas escolas públicas".

Muitas ações políticas - educacionais de inclusão, têm sido implantadas nestas últimas décadas. E, como conseqüência deste processo, em abril de 2008, a plenária final da Conferência Nacional da Educação Básica aprovou a construção de um sistema de educação inclusivo, proposto e defendido como política pública do Ministério da Educação, rejeitando a proposta de continuidade da oferta de escolas e classes especiais para substituir a escolarização. 
Com o objetivo de contribuir para a melhoria da formação dos professores e alunos, foi criada, em 2008, pela Secretaria de Educação Especial - SEESP/MEC, a Rede Nacional de Formação Continuada de Professores. Este programa é constituído por 16 instituições públicas de ensino superior, federais e estaduais, que oferecem cursos de capacitação em Educação Especial à distância, com o propósito de atender a demanda nacional de professores da rede municipal e estadual de ensino básico. Destas instituições, apenas uma delas oferece o curso de capacitação para a área Educação Física. O CENSO Escolar MEC/INEP de 2009, apontou que o Brasil apresentava 1.572.000 professores no ensino básico e que apenas 66.529 possuíam formação na área da Educação Especial.

Buscando amenizar essa situação, a constituição da Rede de Formação foi para implementar o Programa de Formação Continuada de Professores na Educação Especial, compondo as ações do Plano de Desenvolvimento da Educação efetivados em cooperação com os sistemas de ensino, que visam ampliar a formação docente para a organização das escolas em consonância com a Política Nacional de Educação Especial na Perspectiva da Educação Inclusiva de 2008. O programa contempla, até os dias atuais, a oferta de cursos, tanto em nível de aperfeiçoamento - 180h, como em nível de especialização - 360h. Cada universidade contempla com cursos de capacitação à distância, cerca de 2000 (dois mil) professoresłano.

No ano de 2012, a SEESP ampliou tanto seus objetivos quanto as políticas públicas, transformando-se na atual Secretaria de Educação Continuada, Alfabetização, Diversidade e Inclusão (SECADI), mantendo o programa e ampliando o programa acima citado.

Nos últimos anos, é inegável o crescimento do acesso dos cidadãos de um modo geral, à escola, seja ela pública ou particular. Os dados do último CENSO Escolar, referente ao ano de 201l, demonstraram um aumento constante no número de matrículas na escola regular, dos alunos com deficiência. Assim, enquanto em 2010 ocorreram 702.603 matrículas, em 2011 houve um aumento de 7\% neste número, chegando a 752.305 alunos. Por outro lado, nas escolas especiais ocorreu uma diminuição de $11,2 \%$ no número de alunos, evidenciando-se um possível êxito da política de inclusão na educação básica brasileira, pelo menos no que diz respeito ao acesso dos alunos às escolas.

Contribuindo com este diagnóstico, a Educação Física aparece em muitos estudos como fator de grande potencial para a inclusão. Porém ainda, pouco implementada para responder ao desafio da Educação Física Inclusiva.

É possível identificar um confronto entre os objetivos da inclusão escolar e da Educação Física e a função social atribuída à escola (CARMO, 2011). Na mesma perspectiva de confronto, a falta de respostas claras e objetivas acerca do processo de inclusão escolar brasileiro, pode gerar práticas educacionais equivocadas e que não atendem aos princípios da inclusão. Da mesma maneira, esses equívocos também podem ser atribuídos às dificuldades epistemológicas e conceituais que acompanham a 
Educação Física somada às diversas formas de se compreender e praticar a inclusão, além de serem influenciadas pela obrigatoriedade em se cumprir programas impostos pelas Secretarias de Educação, que em sua maioria são compostos por avaliações, comparações e conteúdos obrigatórios.

Diante disto, apresentamos a seguir, uma proposta de trabalho com a Educação Física Inclusiva.

\section{Proposta de educação física inclusiva}

A inclusão de alunos com deficiência nas aulas de Educação Física é uma realidade cada vez mais marcante. Sendo assim, desenvolver atividades inclusivas passou a ser uma necessidade.

Estamos vivendo um momento, no qual, a sensibilidade individual e coletiva em relação à diversidade humana, tem proporcionado um maior comprometimento dos professores de Educação Física com suas aulas e, consequentemente, colaborado para a efetivação e participação dos alunos com deficiências nas atividades curriculares.

É importante ressaltar que, segundo Ferreira (2003), as relações sociais, não mudam somente por decretos de lei. O modo como elas se dão é histórico e muda conforme se criam novas condições para que as mesmas aconteçam. Sem dúvida, a Educação Física é um lugar possível para a pessoa com deficiência instituir novas sociabilidades e novas subjetividades no mundo atual.

Ao longo da história, muitos dos espaços sociais foram negados à pessoa com deficiência e entre eles, o espaço escolar, em especial nas aulas de Educação Física, que se apresenta como um foro para celebrar as diferenças corporais, oferecendo a oportunidade de res-significar, fortalecer e divulgar valores e manifestações que perpetuem a expressão de identidades, contribuindo para a promoção, valorização e salvaguarda da cultura e do direito do cidadão brasileiro.

Trabalhar com a Educação Física inclusiva não é algo simples. Não é apenas adaptar gestos corporais, nem tão pouco, um afrouxamento do rigor e das exigências técnicas para o desenvolvimento de qualquer atividade. Ao contrário, o exercício da prática corporal requer uma instrumentalização capaz de propiciar a construção de uma ordem de movimentos adequados à percepção de padrões estruturantes de uma técnica; técnica esta, que permita a realização de movimentos que façam sentido para as pessoas com e sem deficiência.

Assim, é inevitável admitir que sugerimos a substituição de um padrão de relativa estabilidade na abordagem da Educação Física e do Movimento, por algo que ainda ressoa com estranheza. No entanto, é a partir dos princípios pedagógicos desta 
mesma Educação Física, que pretendemos erigir outra dimensão de trabalho/movimento. É dela que precisamos extrair uma ordem, de possibilidades corporais.

A partir dos pontos acima observados, esta pesquisa aponta, então, uma possível proposta de Educação Física inclusiva:

1 - É importante promover discussões no interior de cada escola, sobre: a) a importância da participação efetiva de toda a comunidade escolar para se alcançar uma escola inclusiva; b) a relevância social de uma Educação Inclusiva; c) as estratégias didáticas e diversas possibilidades de acessibilidade e tecnologias educativas.

Para tal, se faz necessário apresentar informativos sobre a viabilidade de uma Educação Inclusiva, demonstrando que a inclusão é possível e que o principal meio para atingi-la é o comprometimento de todos os envolvidos na organização da escola, na capacitação dos recursos humanos e na orientação dos pais e dos alunos;

2 - Nas aulas de Educação Física, os alunos com e sem deficiência devem participar conjuntamente das aulas e tarefas propostas, embora também seja necessário, haver, em momentos complementares, atividades separadas que contemplem as especificidades de cada aluno, buscando que o mesmo, desenvolva habilidades que lhe permitam um maior sucesso na execução das mesmas.

Assim, todos os alunos devem ser considerados sujeitos do processo inclusivo, onde as diferenças devem ser amenizadas e, independente das dificuldades e do ritmo de aprendizagem de cada um, a diversidade deve constituir-se como um valor educativo. Vale ressaltar ainda, que, de acordo com Sassaki (1999), a inclusão social é o processo pelo qual a sociedade se adapta às necessidades da pessoa com defi-ciência para inclui-la e prepará-la para participar ativamen -te da vida na sociedade;

3 - O planejamento escolar da disciplina em questão deve ser amplo e comum a todos, buscando dar respostas educativas com respeito às diferenças, sempre o reavaliando de acordo com as habilidades motoras e sociais de cada turma. Além disso, é necessário propor práticas pedagógicas na interface entre todas as disciplinas curriculares.

Diante disso, a discussão de programas de aulas como elemento fundamental que orienta e guia o processo de ensino-aprendizagem, deve fazer parte das reuniões pedagógicas escolares, pois a programação inclui todas as unidades didáticas.

4 - É necessário quebrar com o paradigma da Educação Física Adaptada, que atua com os esportes de alto rendimento, já que eles devem ser treinados em ambientes externos à escola. No entanto, é fundamental desenvolver os princípios pedagógicos dos mesmos, buscando inter-relações entre as modalidades. 
Desse modo, é importante apontar que a Educação Física é um espaço que possibilita trabalhar as diferenças corporais, oferecendo a oportunidade de resgatar, fortalecer e divulgar as potencialidades e habilidades de cada aluno, preparando-os para atuarem na sociedade com seus olhares voltados para a diversidade.

Temos então, que para se obter a igualdade de oportunidade na participação dos alunos nas aulas de Educação Física é primordial estabelecer critérios gerais para todas as atividades físicas e o esporte, buscando alcançar êxito pelos participantes. Além disso, é direito das pessoas com deficiência, como parte do seu desenvolvimento e bem estar, desfrutar das atividades de recreação, artística e esportiva junto com as pessoas sem deficiência e não mais, separada`mente da população geral.

Vale ressaltar que, corpos diferenciados estão conquistando um novo espaço social. Isto nos dá indícios de que, embora trabalhar com respeito à individualidade, numa perspectiva de cooperação, ainda seja uma dificuldade para os profissionais da área, o advir é desafiar tanto os modelos congelados da Educação Física, quanto estes profissionais para atuarem em novas construções pessoais, esportivas e sociais.

\section{Considerações finais}

A Educação Física inclusiva tem preconizado outro signi_ficado de corpo. Prevalece em suas atividades, a busca do individual, em prol de uma Educação Física mais coletiva. Nesta perspectiva, o corpo deixa de ter um entendimento mais focado em sua dimensão biológica e passa a valori-zar as possibilidades de movimento e a convivência social.

A proposta deste estudo passa assim, necessa riamente, por práticas/vivências corporais que supõem uma colaboração estreita entre professores e alunos. Os objetiาvos pedagógicos estão sendo estabelecidos a partir das pos`sibilidades de cada discente e ao se iniciar uma atividade prática, a mesma precisa ser demonstrada, discutida, sabo-reada e desejada pelos alunos. Os professores, normalmen $\neg$ te acostumados a um trabalho individualista, são chamados, neste contexto, a se interrogar sobre suas prioridades de educadores e sobre os meios que privilegiam. Eles devem se abrir à análise crítica, para recolocar em questão a forma ‘ção prática das vivências corporais e desenvolver novas leiıturas do corpo e dos novos modelos de formação.

Para os alunos com deficiência, as práticas corporais enriquecem suas experiências, independente da sua capacidade motora, tipo de deficiência e grau de comprometimento, o que torna necessário permitir um horário com flexibilidade e variar a duração de uma aula de acordo com as exigências de cada atividade proposta, que não pode mais ser li`mitada e definida. É necessário sempre rever os princípios que subentendem o movimento. O professor pre-cisa, então, buscar soluções pedagógicas para que a partici־pação dos alunos com deficiência seja efetiva, conforme propusemos aqui. 
Enfim, a Educação Física Inclusiva é um desafio que po-de/deve ser plenamente cumprida. Porém, para isto, é fundamental quebrar/desestabilizar com as práticas corporais já cristalizadas e atuar com aquelas que respeitam as diferenças de cada um. São inúmeras as possibilidades, mas o sucesso de cada uma depende de experimentação contínua.

\section{Referências}

AMARAL, L. A. et.al. Propondo uma política da USP referida à deficiência. Disponível em: $<$ http://usplegal.saci.org.br/quem/Propondo_uma_Politica_da_USP_Referida_à_Deficiência_htm>. Acesso 20 set. 2012.

BISSOTO, M. L. Educação inclusiva e exclusão social. Revista Brasileira de Educação Especial, 2013 v. 26 (45). São Paulo, 2013. ISSN 1413-6568 p. 91-108.

BRASIL. Conferência Nacional de Educação Básica. Brasília, DF: MEC, 2008. Disponível em: 〈http:// www.ufvjm.edu.br/arquivos/64/22/CPA_Sinaes_Plano_Desenvolv_Educacao_Haddad_2008.pdf). Acesso em: 8 nov. 2012.

BRASIL. Constituição Federativa do Brasil, (art. 227, $\$$ 1º $^{\circ}$ II, da CF/88). Brasília, DF. 1988. Disponível em: 〈http://portal.mec.gov.br/dmdocuments/escolaqueprotege_art227.pdf 〉. Acesso em: 05 dez. 2012.

BRASIL. Diretrizes e Bases da Educação Nacional. Lei n. 9.394. Brasília, DF. Disponível em: ‘www.mec. seesp.gov.br>, 1996.

BRASIL. INEP. Resumo Técnico do Censo da Educação Básica 2009. Disponível em: ‘http://download. inep.gov.br/download/censo/2009/TEXTO_DIVULGACAO_EDUCACEEDU_20093.pdf〉. Acesso em: 12 nov. 2012.

BRASIL. INEP. Resumo Técnico do Censo da Educação Básica, 2011. Disponível em: 〈http://download.inep.gov.br/educacao_basica/censo_escolar/resumos_tecnicos/resure_tecnico_censo_educacao_basica_2011.pdf). Acesso em: 12 nov. 2012.

BRASIL. Ministério da Ação Social. Política Nacional de Integração da Pessoa Portadora de Deficiência. Brasília, CORDE, 1992.

BRASIL. Ministério da Educação. SECADI - História. Disponível em: ‘http://portal.mec.gov.br/index. php?option=com_content\&view=article\& $\&$ id=2\& Itemid=17). Acesso em: 5 dez. 2012.

BRASIL. Ministério da Educação. Secretaria de Educação a Distância. Disponível em: 〈http://portal.mec. gov.br/index.php?option=com_content\&view=article\& $\&$ id=289\&ะItemid=356>. Acesso em: 5 dez. 2012.

BRASIL. Ministério do Esporte. Histórico. Disponível em «http://portal.esporte.gov.br/institucional/historico.jsp’. Acesso em: 5 dez. 2012.

BRASIL. O Plano de Desenvolvimento da Educação: razões, princípios e programas / Fernando Haddad. - Brasília: Instituto Nacional de Estudos e Pesquisas Educacionais Anísio Teixeira, 2008.

BRASIL. Plano Nacional de Educação 2001-2011. Brasília: Congresso Nacional, 2001.

BRASIL. Política Nacional de Educação Especial na Perspectiva da Educação Inclusiva. Ministério da Educação, Secretaria de Educação Especial, Brasília, DF. Disponível em: 〈www.mec.gov.br/seesp〉, 2008.

BRASIL. Presidência da República. Decreto n. 93.613 de 21 de novembro de 1986. Disponível em: < http:// www.planalto.gov.br/ccivil_03/decreto/Antigos/D93968.htm>. Acesso em: 2 dez. 2012. 
BRASIL. Presidência da República. Decreto n. 8.028 de 12 de abril de 1990. Disponível em: 〈http://www. planalto.gov.br/ccivil_03/leis/L8028.htm>. Acesso em: 2 dez. 2012.

BRASIL. Presidência da República. Lei n. 10.048 de 8 de novembro de 2000. Disponível em: ‘http://www. planalto.gov.br/ccivil_03/leis/110048.htm>. Acesso em: 2 dez. 2012.

BRASIL. Presidência da República. Lei n. 10.098 de 19 de dezembro de 2000. Disponível em: < http://www. planalto.gov. br/ccivil_03/leis/L10098.htm>. Acesso em: 2 dez. 2012.

BRASIL. Presidência da República. Lei n. 6.094 de 24 de abril de 2007. Disponível em: < http://www. planalto.gov.br/ccivil_03/_ato2007-2010/2007/decreto/d6094.htm>. Acesso em: 2 dez. 2012.

BRASIL. Presidência da República. Lei n. 6.251 de 8 de outubro de 1975. Disponível em: < https://www. planalto.gov.br/ccivil_03/leis/1970-1979/1625l.htm>. Acesso em: 2 dez. 2012.

BRASIL. Presidência da República. Plano Nacional de ação conjunta para integração da pessoa deficiente: 1985. Rio de Janeiro, 1985.

BRASIL. Secretaria de Educação e Desportos. Teoria e prática dos esportes para todos 1982-1983. SEED/ SUEP, Brasília, MEC, 1983.

BRASIL. Secretaria de Educação e Desportos. Teoria e prática dos esportes para todos 1982-1983. SEED/ SUEP, Brasília, MEC, 1983.

CALVALCANTI, K. B. Esporte para todos: um discurso ideológico. São Paulo: IBRASA, 1984.

CARMO A. A. Aspectos históricos filosóficos e sociológicos da deficiência. In: FERREIRA, E. L. (Org.). Atividades Físicas Inclusivas para pessoas com Deficiência. Niterói: Intertexto, V. 1, 2011.

CARMO A. A. Atividades Físicas Inclusivas. In: FERREIRA, E. L. (Org.). Atividades Físicas Inclusivas para pessoas com Deficiência. Niterói: Intertexto, V. 7, 2011.

CARMO A. A. Estigma, corpo e deficiência. Revista Brasileira de Ciências do Esporte, v. 9, (3). São Paulo, 1988. ISSN 0101-3289.

CARTA DE BATATAIS. In: Encontro de Avaliação do Subprograma de Recursos para a Educação Especial, v. 1, Batatais,1986.

ECHEITA, G. Los dilemmas de las difrencias en la educación escola. In: ANAIS VII JORNADA CIENTÍFICAS DE INVESTIGACION SOBRE PERSONAS COM DISCAPACIDADE.7, 2009, Salamanca, anais ... Salamanca: Amarú, 2009.

FERREIRA, E. L. As formas dos discursos da/na dança em cadeira de rodas e seus processos de significação. 2003. Tese (Doutorado) - Faculdade de Educação Física, Universidade Estadual de Campinas, Campinas.

ORGANIZAÇÃO DAS NAÇÕES UNIDAS. Carta Internacional da Educação Física e Desportos: 20ª Reunião da Conferência Geral da Organização das Nações Unidas para a Educação, a Ciência e a Cultura: Paris, 1978.

SASSAKI, R. K. Inclusão: Construindo uma sociedade para todos. Rio de Janeiro: WVA Editora, 1999.

VALENTE, E. Esporte... para todos? Maceió, Edufal, 1997. 


\section{Correspondência}

Eliana Lúcia Ferreira - Universidade Federal de Juiz de Fora, Faculdade de Educação Física, Departamento de Fundamentos da Educação Física, Rua Benjamin Constant, 790, Centro, CEP: 36015-400

Juiz de Fora, Minas Gerais, Brasil.

E-mail: eliana.ferreira@ufjf.edu.br - equipepedagogica.gime3@uab.ufjf.br

Recebido em 12 de janeiro de 2013

Aprovado em 19 de setembro de 2013 